\title{
Editorial
}

\section{Future Education: Schools and Universities}

The University is, increasingly, a ghostly institution. It is haunted not only by questions concerning the nature of teaching, but also by a sense of its relationship to itself and to its own past ... Directives come from the phantom of 'the centre' ... The University is in ruins.

Nicholas Royle, The Uncanny, p. 54.

While some may argue that universities are in a state of crisis, others claim that we are living in a post-university era; a time after universities. If there was a battle for the survival of the institution, it is over and done with. The buildings still stand. Students enrol and may (at times) attend lectures, though let's be clear-most do not. But virtually nothing real remains. What some mistakenly take to be a university is, in actuality, an 'uncanny' spectral presence; 'the nagging presence of an absence ... a "spectralized amnesiac modernity with its delusional totalizing systems"' (Maddern \& Adey 2008, p. 292). It is the remains and remnants of the university. ${ }^{1}$

Overstatement? Perhaps. We think many if not most administrators, at all levels, will likely dissent. So too will many if not most teachers and students. Trying to determine whether this is correct, or to what extent, by consulting polls and reading opinion pieces in various education journals and professional papers (e.g. Journal of Higher Education; The Campus Review; Chronicle of Higher Education) is likely to be of little help. In any case, it is the hypothesis (that universities and educational institutions generally are in a state of crisis), along with closely related ones, and concerns about what can be done in the circumstances, that have generated this special issue.

This special issue highlights and illustrates that most of the contested issues regarding educational theory and practice central to how universities and schools should be, and how they should be run, are first and foremost questions of value

1 See Cox and Levine (2016a, b) and Boaks, Cox and Levine (forthcoming). 
rather than fact. They are questions regarding what we want, but more importantly what we should want, from our universities and schools; about what they should be and what students, teachers and administrators should be doing to facilitate this.

Simultaneously there is a complaint that students in primary and high schools are less engaged. Operating in a time of mass art, media and technology that monopolises and mediates citizens' access to information and images, educational institutions and teachers are playing catch-up while governmental policies seek to test and measure everything in sight. This measuring and judging is often undertaken with questionable criteria or criteria (e.g. student evaluations) shown to be misleading if not mistaken. Students are distracted and access more 'knowledge' as independent learners than ever previously. This raises fundamental questions as to the role of the teacher and the classroom, and how philosophy of education might best serve pedagogical practices that help prepare students for life and employment. Such questions are set against a time of rapid technological advancement in which jobs of the future, communication devices and technical wizardry and AI is such that we can barely imagine.

The ongoing neoliberalisation of public services has brought about significant operational and structural transformations in education. The focus on outcomes and outputs sees researchers having to justify any research they do in terms of economic and political gains prior to being granted any funding, while teachers themselves are assessing, measuring and testing students incessantly from primary school age. Such assessment often uses contested metrics, resulting in 'outcomes' that are also contested in terms of desirability and feasibility. The neoliberal agenda forgets the social, moral and personal implications, only counting the costs but unable to measure the benefits of such considerations. Furthermore, the neoliberal agenda fails to account for the virtues of researchers and teachers as well as students - all of whom operate as members of various communities.

Neoliberals (and neoconservatives) believe in what Carmen Lawrence $(2005 ; 2006)$ has called 'the just world hypothesis': 'You get what you deserve and you deserve what you get'. Is it any surprise that the kind and extent of changes for the worse that have been wrought in higher education, as elsewhere, are often motivated by basic needs and affects (e.g. greed and power; jealousies; fear of missing out (FOMO) or of being taken advantage of; or a sense of entitlement)? Rarely acknowledged, these real underlying psychological reasons (causes) are then rationalised and transformed into public policy justifications (e.g. it is unaffordable; the sector fears 
change, etc.). The managerialism and move to business models that now have a stranglehold on universities and school systems can be seen as a manifestation of the politics and 'spirit' of the age.

This special issue of Journal of Philosophy in Schools seeks to address normative, ethical and practical questions regarding the future of educational spaces, including schools (primary and secondary) and the University. We asked that essays be largely conceptual and argumentative, but also empirically informed. The topics and themes we explicitly sought were as follows:

- Are universities any longer necessary? Is the University a thing of the past and if so, what has or should have taken its place?

- What are some of the social, political and personal implications of the radical changes schools (primary or secondary) or universities have already undergone and of what they are becoming?

- Is there a distinctive set of what may be termed the academic virtues or virtues of teachers? If so, what are they? Is it possible to practice those virtues, to be a person of good character, in the context of the day-to-day life of the contemporary university or school environment? In short, is teaching at a university or school compatible with integrity?

- What, if anything, is it about the nature or structure of the new managerialism in universities and schools, and perhaps neoliberalism and neo-conservatism in society at large, that may be inimical to the value and function of education?

- What might the university or the school of the future look like? How will it function? What will be its role? Have any of the 'traditional' values and purposes of education survived the transformations already undertaken, let alone those to come?

- Why teach at the Future School or University? Will teaching at the Future School or University be desirable? Can it be (remain) a vocation or is it better seen as a job?

- What, if anything, is the relation between the fact that teachers no longer have the say (power) they once did in administration have to do with the shaping of the Future School or University? 
- Relatedly; supposing that, in particular, university teachers, are no longer highly regarded either within society or (arguably) by university administrators at the highest level, what are the implications of this for the Future University in terms of teaching, learning and the so-called university experience? Similarly the pressure on teachers to ensure students get good grades has increasingly seen governments, schools and parents place the responsibility and the blame on teachers rather than on the students and their home environments. What is the implication of this on the Schools of the Future?

- Must the meaning of 'education' and what it means to be educated be revised and contextualised given what schools and universities have become - or are becoming?

- Describe the University of the Future or describe the School of the Future. What does it see itself as becoming and how does that differ, if at all, from what it should become?

The articles included in this special issue have answered the call and address these topics (usually several of them) both directly and indirectly. This special issue includes five original articles, authored by nine individuals, as well as a book review.

Damian Cox (Competition, contest and the possibility of egalitarian university education) asks: 'What would an egalitarian future for higher education look like' and how can it be achieved? He argues for profound 'reforms of academic institutions that would diminish the prevalence of destructive competition and approach more nearly the egalitarian goal of treating all members of the academic community ... as equally valued and equally deserving of respect'. According to Cox, this goal is not merely desirable but (arguably) also necessary for the future well-being of universities. (They are not well now). At least two things-though there are of course more-are needed to achieve this goal. The first is a radical revision of student assessment; namely, a move to a rigorous pass-fail system rather than grades. Whether or not such a move is even possible given the current state of universities and relevant social and political conditions is suspect-and left, for the time being, aside. The consequences of such a move would be far-reaching and Cox discusses what he takes to be some of the consequences of such a change. 
The second and perhaps more basic thing that needs to be undertaken is a reevaluation and adjustment of the university's duties to employers and the wider community. There is at least an underlying suggestion that for any of this to happen the nature of the university itself, and especially its move to managerialism and business models, should be challenged and changed. Contestable values and ethical issues are at stake. Until decisions are made as to what it is universities should be trying to achieve for their many stakeholders, questions about how to achieve them are beside the point. There are few, if any, of the questions suggested for the special issue (above) that Cox's article does not at least implicitly address.

Rachel Buchanan and Amy MacPherson (Teachers and learners in a time of big data) begin 'with a critical examination of constructions of teachers, learners and the digital data-driven educational culture in order to explicate the futures being generated', as well as surveying the current problematic state of affairs in education. In ways at times similar to Cox, they are concerned with a 'metrics driven approach to education' - an aspect of what they term 'datafication'. Along with (and as a part of) 'technological surveillance', this has enabled new and 'sophisticated forms of governance' of teachers and students alike. And it has done this in somewhat insidious ways; by reconstructing their 'subjectivities and professional identities' the roles they play in education systems.

These features of current educational systems are at the core of the 'massive changes to educational systems over the past two decades' - changes that have been anything but good for education and those who are a part of it. On a positive note, they claim that 'Alternative conceptualisations of the future of schooling are possible which offer ways of understanding and politicising what happens when we impose datadriven accountabilities into people's lives'. Presumably, along with alternative conceptualisations to the now dominant digital data-driven educational culture comes the possibility (no matter how unlikely given the current forces at play) of educational systems not only very different from, but far better than, those now in place.

As with Cox, Buchanan's and MacPherson's article is clearly argued and impassioned. Both articles are responding to what the authors see as important issues of competing values. Neither think that 'all is well' - far from it. In response to the question, 'What is the future of our educational institutions?' we can see that policy matters-and policy is driven by normative (evaluative) decisions. The question, 'What do we want and what should we want for educational institutions in 
the future?' is so important that it can be seen as another way of asking, 'What future do we want?'

Iris Huis in't Veld and Michael Nagenborg (It's getting personal: The ethical and educational implications of personalised learning technology) explore the role of personalised learning systems in education. In an increasingly technological world, such systems allegedly predict learning needs to tailor education to the unique requirements of individual students. But what is meant by 'personal' and personalisation may differ when considered from an educational perspective versus a technological one. The differences are in no small part differences of value. They contain not only alternate understandings of student autonomy, but also of learning and education. 'Personalised learning technology, therefore, bears the risk of failing to achieve its educational ideal of what personalisation should be', they argue. Technology is needed, but it has to be value driven on the one hand, while protecting the autonomy of students (and presumably teachers) on the other.

It seems difficult to argue with the idea that 'personalised learning systems, systems that predict learning needs to tailor education to the unique learning needs of individual students' is a good thing. While not denying that personalised learning is desirable (depending on just what is meant by 'personal' and how it is applied in such systems), the authors argue that there is great deal both theoretically and practically to object to and to be cautious of, given how such systems are thought about and deployed. Huis in't Veld and Nagenborg claim that 'schools should avoid falling for "solutionism" by using technology to change education without understanding the problem first'. Where adaptive learning technology tailors education to suit a student's needs by using predictive analytics, this technological definition of 'personal' undermines educational goals such as choice and agency. Furthermore, the intensive tracking and surveillance used by such technology exposes students to privacy and data protection risks. A more general question the authors raise is just how much learning, and what kinds of learning should be personalised? It is a tricky issue, but one worth exploring further, as to how educational goals may remain personalised in terms of objectives, and shaped by varying degrees of ability and interest (of both students and teachers), while also remaining more general. An example of the latter is the educational goal to further autonomous and creative thinking-and cultivate informed and morally sound citizens. It is an open question as to how technology may assist us with goals such as these. 
Mitch Parsell and Christine Chinchen (The evolution of learning: Post-pedagogical lessons for the future university) offer a post-pedagogical image of universities. Grabbing the theme of the special issue with both hands, the authors focus on placing learning at the heart of the educational institution, with dual goals in mind: 'creating an educated public and preparing learners for future careers'. Drawing upon neo-Aristotelians Alasdair MacIntyre and Martha Nussbaum, Parsell and Chinchen claim that universities need to educate for a responsible citizenry, and this involves teaching students to think for themselves. Such thinking skills require critical thinking, critical looking, and critical imagination. With the future of work in a state of transition due to rapid technological change, the skills required for the future employee, they claim, include smart learning, smart thinking, and smart doing. Universities will not be able to meet such demands while they 'remain fixated on an authoritative, transmission model of education', or while they assume 'that the ability to create learning opportunities for others automatically arises from subject content expertise'.

In a synthesis of the ideas explored above, Parsell and Chinchen imagine the future university as providing students with learning experiences that develop meaningful thinking, meaningful learning, and meaningful acting. This includes working effectively with technology, engaging in reasoned debates, acting appropriately in the world, embracing continuous learning, seeing oneself as an interdependent learner amongst others, and being able to imagine the future and oneself differently, given that the future is not fixed or knowable in a pre-determined manner. When read alongside the other papers, the image of this post-pedagogical learning space is fleshed out, detailed with warnings as to what needs to be avoided, as well as illuminating what we ought to embrace.

Anna Hush and Andy Mason (Education as the practice of freedom, from past to future: Student movements and the corporate university) provide us with the fifth and final article in our special issue. They also provide us with a new and different perspective: that of the student. Beginning with a wide-ranging critique of contemporary universities as driven by neoliberal agendas, the main focus of this article is to describe ways in which 'student organisers, working in coalition with academics, unions and communities ... [could help shape] the Future University'. They also describe ways in which student unions and organisers have already moved the University (especially the University of Sydney) in desired directions. Hush and Mason recognise that 'the rapid neoliberalisation of universities presents both barriers and possibilities for those seeking to mobilise students in service of 
both struggles for educational justice, and for broader community campaigns'. With a clear emphasis on action and grassroots movements, the authors connect theory to practice, demonstrating the very real impact education may have in the world.

There is no doubt that students and student organisations, including unions, working in connection with faculty and broader political institutions can be a powerful and positive force for change. How successful they have been is contestable and may rest upon a case-by-case analysis, and the extent to which they can disrupt the neoliberal agenda is equally open to heated debate. Consider, for example the fact that students have themselves been co-opted to a great degree by neoliberalism. Being a neoliberal (embodying some even if not all of their values and views) and being a student are, of course, not incompatible. Aspects of what students have helped administrations fight for and win-like mandatory recording of lectures and student evaluation of teaching-arguable have undermined their alleged agenda of 'shaping the Future University, through grassroots advocacy for staff working conditions, and for critical pedagogies that enable the integration of transformative social justice movements with academic theory'. To offer a cynical counter argument, it is difficult to see how complaints about the quality of 'student experience' can be squared with students so infrequently attending lectures on campus. And it is difficult to see how teaching is markedly improved by the frequent evaluations (student evaluations and surveys, peer-review, annual line manager reviews and reviews for promotion) to which time-poor teachers are subject, only to be judged by unfair metrics such as the grades their students received or the extent to which they are extroverted or fashionable.

It is easy to agree with Hush and Mason that '... student movements need to construct a positive vision of what the future university ought to be ... for the importance of love to education, and for "passionate teaching and learning" that treats students not as disembodied and purely rational beings, but as holistic subjects with the potential for emotional and political engagement in the educational process (hooks 1994, p. 199)'. The question for many academics is whether or not students have been so confused and co-opted by the neoliberal agenda that they any longer (collectively) have this 'positive vision'. Hush and Mason's final, rallying cry is aimed at students, but applies equally to academics, and to policy makers, administrators and professional staff: 'We have raised many reasons for students, staff and communities to be concerned with the neoliberalisation of tertiary education, including poor working conditions, decreasing quality of learning, and attacks on student unions. However, as we have argued, these conditions at the 
same time provide a fertile ground for political dissent'. If such political action may be combined with love and passion, there is still hope for the future of schools and universities.

This issue also contains a book review. Phil Cam has reviewed Michael Hand's $A$ Theory of Moral Education (Routledge, London, 2018).

Michael P Levine (Guest Editor) and Laura D'Olimpio

\section{References}

Boaks, J, Cox, D \& Levine, MP (forthcoming) Integrity and the university: Traps for old players. Knowledge Cultures.

Cox, D \& Levine, MP (2016a) Academic virtues: Site specific and under threat. Journal of Value Inquiry, 50(3), pp. 753-767.

Cox, D \& Levine, MP (2016b) Welcome to SU: The Spectral University. Angelaki: Journal of the Theoretical Humanities, 21(2), pp. 213-226.

Hand, M (2018) A theory of moral education. Routledge, London.

hooks, b (1994) Teaching to transgress: Education as the practice of freedom. Routledge, New York, NY.

Lawrence, C (2005) Fear and public policy. Freilich Foundation Lectures, Australian National University, Canberra, Australia. 8 November, 2005. Available from: http://www.safecom.org.au/freilich-lectures1.htm

Lawrence, C (2006) Culture of fear or fairness. ACOSS Annual Congress. Sydney, Australia, 23-24 November, 2006.

Maddern, JF \& Adey, P (2008) Editorial: Spectro-geographies. Cultural Geographies, 15, pp. 291-295.

Royle, N (2003) The uncanny. Routledge, New York, NY. 